\title{
Acute kidney injury associated with COVID-19 infection: a case report
}

\author{
Tiago Duarte $^{1}$ (D), Fernando Caeiro 2 iD, Mário Góis 2,3 iD, António Matos ${ }^{4,5}$ iD, Helena Viana 2,3 iD, César Vieira ${ }^{1}$ iD, Jorge Paulos ${ }^{1}$ iD, \\ Paulo Paixão ${ }^{6}$ iD, Bruno Matos ${ }^{7}$, Nuno Germano ${ }^{1}$ (iD), Fernando Nolasco ${ }^{2}$ iD \\ ${ }^{1}$ Unidade de Cuidados Intensivos Centro Hospitalar Universitário de Lisboa Central, Hospital Curry Cabral, Lisboa, Portugal \\ ${ }^{2}$ Serviço de Nefrologia Centro Hospitalar Universitário de Lisboa Central, Hospital Curry Cabral, Lisboa, Portugal \\ ${ }^{3}$ Laboratório de Morfologia Renal Centro Hospitalar Universitário de Lisboa Central, Hospital Curry Cabral, Lisboa, Portugal \\ ${ }^{4}$ Egas Moniz - Cooperativa de Ensino Superior CRL, Lisboa, Portugal \\ ${ }^{5}$ Centro de Investigação Interdisciplinar Egas Moniz. Centro de Microscopia Electrónica e Histopatologia Egas Moniz. Campus Universitário, Monte de Caparica, Portugal \\ ${ }^{6}$ Microbiologia, Nova Medical School, Lisboa, Portugal \\ ${ }^{7}$ Anatomia Patológica Centro Hospitalar Universitário de Lisboa Central, Hospital Curry Cabral, Lisboa, Portugal
}

\section{ABSTRACT}

SARS-Cov2 infection is a highly transmissible disease associated with serious pulmonary disease. Renal involvement is frequent and associated with poor prognosis; however, mechanisms of kidney injury are not well established.

We present a SARS-Cov2 patient with severe acute kidney injury. Kidney biopsy findings revealed a pattern of acute tubular necrosis with isometric vacuolization of the proximal tubule. The interstitium and glomeruli were normal. Electronic microscopy showed multiple viral-like particles in both the glomeruli and proximal tubule.

This case study shows how SARS-Cov 2 infection can result in different kinds of kidney lesion.

Key-words: acute kidney injury, COVID-19, kidney biopsy

C 2021 Portuguese Journal of Nephrology \& Hypertension. Published by Publicações Ciência \& Vida This is an open access article under the CC BY-NC-ND license (http://creativecommons.org/licenses/by-nc-nd/4.0/).

\section{INTRODUCTION}

Novel coronavirus disease (COVID-19) is a newly discovered disorder declared a global pandemic by the World Health Organization (WHO) on March 11, 2020. Its pathogen, severe acute respiratory syndrome coronavirus 2 (SARS-CoV-2), is highly transmissible and primarily injures the vascular endothelium ${ }^{1}$. While it presents predominantly as an acute lung illness, patients eventually develop a multiorgan failure among which the kidney lesion can be particularly challenging ${ }^{2}$.

Clinical manifestations vary, and the exact mechanism of the lesion is still unclear.

We describe a clinical case of acute kidney injury in a severe SARSCov 2 infection and report its' histological findings.

\section{CASE REPORT}

We present the case of a 49-year-old man from India, admitted to our hospital with bilateral SARS-CoV-2 pneumonia in March/2020. He had no previous medical conditions except for being slightly overweight (BMI $27 \mathrm{~kg} / \mathrm{m}^{2}$ ). He presented at the Emergency Room with fever $(39.5 \circ \mathrm{C})$, cough and myalgia for three days, pulmonary auscultation was unremarkable, and his mental status was normal. On admission, blood pressure was $85 / 61 \mathrm{mmHg}$ and heart rate was $85 \mathrm{bpm}$. His laboratory tests showed hemoglobin $11.4 \mathrm{~g} / \mathrm{dL}$, leukocyte count $3.04 \times 10^{9} / \mathrm{L}$ with lymphopenia $0.57 \times 10^{9} / \mathrm{L}$, platelet count 138 $\times 10^{9} / \mathrm{L}$, serum creatinine $(\mathrm{SCr}) 0.83 \mathrm{mg} / \mathrm{dL}$, urea $18 \mathrm{mg} / \mathrm{dL}$, lactate dehydrogenase $429 \mathrm{U} / \mathrm{L}$ and C-reactive protein $9.97 \mathrm{mg} / \mathrm{dL}$. Pulmonary $X$-ray evidenced a bilateral flocculated pneumonia, and the nasopharyngeal swab was positive for SARS-CoV-2 by nucleic acid amplification teste (RT-PCR).

He started treatment with lopinavir/ritonavir, hydroxychloroquine, azithromycin, amoxicillin/clavulanic acid and ascorbic acid (6g/day for a total of $56 \mathrm{~g}$ ) upon admission. However, due to clinical deterioration, he required mechanical ventilation and was admitted to the ICU within 24 hours of admission. Blood cultures, Streptococcus pneumoniae and Legionella pneumoniae antigens and RT-PCR for other respiratory virus were all negative.

His renal function declined rapidly as evidenced by an increase of $\mathrm{SCr}$ to $2.59 \mathrm{mg} / \mathrm{dL}$ and a decrease in urine output within 48 hours and peaking at $\mathrm{SCr} 5.52 \mathrm{mg} / \mathrm{dL}$ on day 5 with anuria. No diarrhea or other 
factors leading to hemodynamic instability were noted; direct nephrotoxic drugs were not given, and a maximum noradrenaline dosage of $6 \mathrm{mcg} / \mathrm{min}$ was administered. Intermittent renal replacement therapy was maintained. Lopinavir/ritonavir was stopped on day 6.

A kidney ultrasound was performed on day 7 , with no lesions found and all complement, ANA, ANCA, anti-GBM and haptoglobin within normal range. Unfortunately, urinalysis was unavailable due to laboratory constraints - they refused urine samples analysis on COVID-infected patients at this time. A kidney biopsy was performed on day 11 to understand the cause of AKI. Paraffin-embedded tissue revealed 30 glomeruli and some medium-sized arteries. Extensive acute tubular necrosis and proximal tubular isometric vacuolization were notable (Figure 1 and Figure 2). Numerous

\section{Figure 1}

Masson's trichrome x40. Acute tubular necrosis without interstitial inflammation.

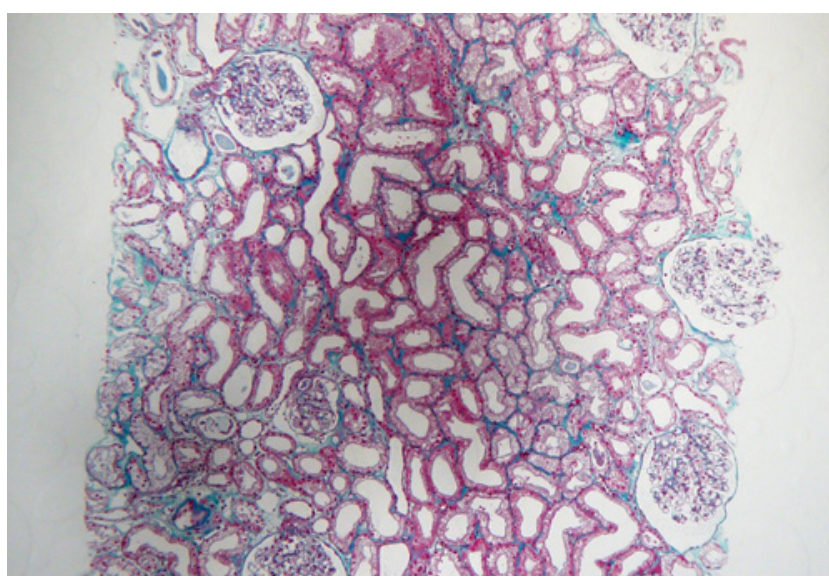

\section{Figure 2}

Masson's trichrome $\times 400$. Acute tubular necrosis with multiple isometric vesicles in the tubular epithelium.

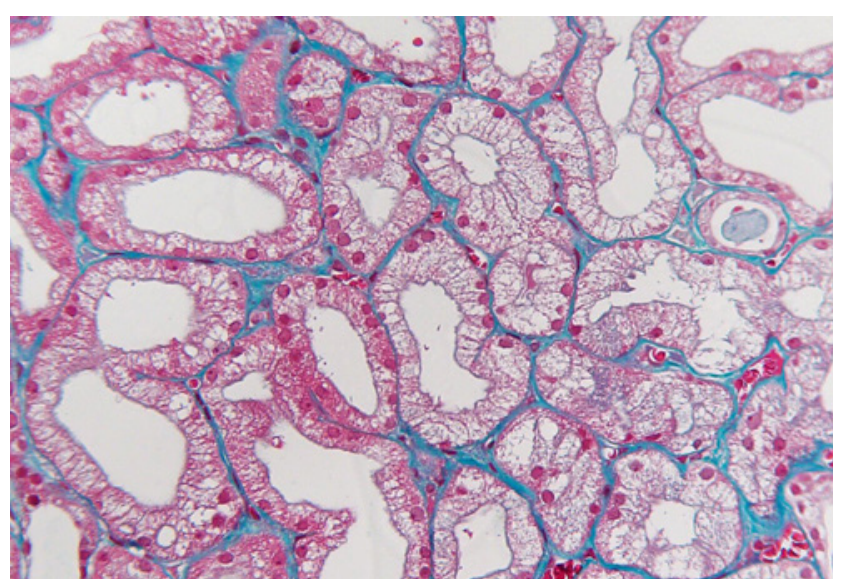

\section{Figure 3}

Hematoxylin eosin x400. Calcium oxalate crystal.

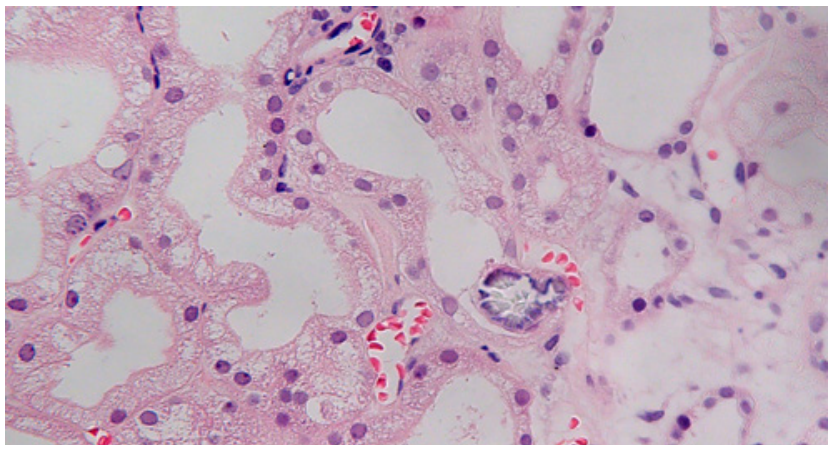

\section{Figure 4}

Hematoxylin eosin x200. Birefringent calcium oxalate crystals under polarized light.

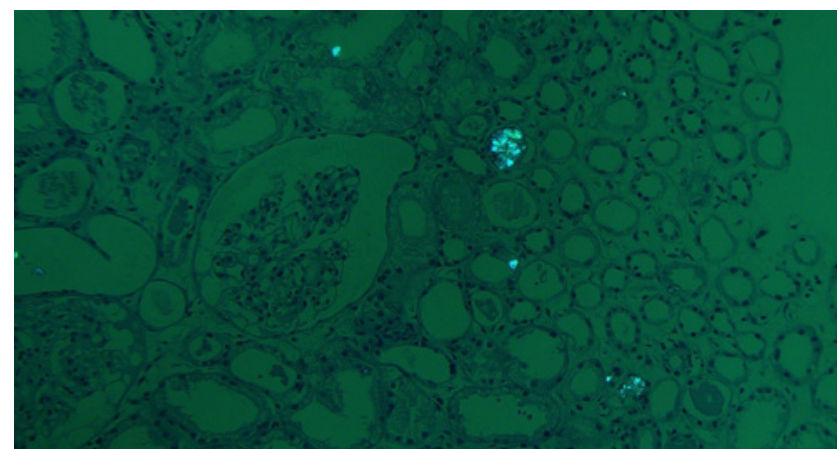

tubules showed birefringent crystals under polarized light, which is a typical feature of calcium oxalate crystals (Figure 3 and Figure 4). Glomeruli and interstitium were normal. Immunofluorescence was negative. Electron microscopy was performed using paraffinembedded tissue. After paraffin removal and re-processing for transmission electron microscopy, thin sections of the glomeruli showed an essentially normal structure. In glomeruli, $100 \mathrm{~nm}$ virus-like particles could be observed in the capillary lumens (Figure 5). Observation of the proximal tubules revealed extensive vacuolization and degenerated epithelial cells with few particles with dimensions of approximately $100 \mathrm{~nm}$ that could represent virus particles (Figures 6 and 7). Some capillaries were clogged with a fibrillar coagulum containing dense masses of unknown nature (Figure 8).

Real-time PCR on paraffin embedded kidney tissue was negative for SARS-COV-2 RNA.

The patient was maintained on supportive therapy, ascorbic acid was discontinued and hemodialysis continued for a month. Ultimately the patient recovered and was discharged with serum creatinine $1.3 \mathrm{mg} / \mathrm{dL}$, and was lost to follow up. 


\section{Figure 5}

Glomerulus. The capillaries remain open and no significant changes in structure can be observed. A few circulating spherical particles with an approximate size of $100 \mathrm{~nm}$ are compatible with virus particle morphology.

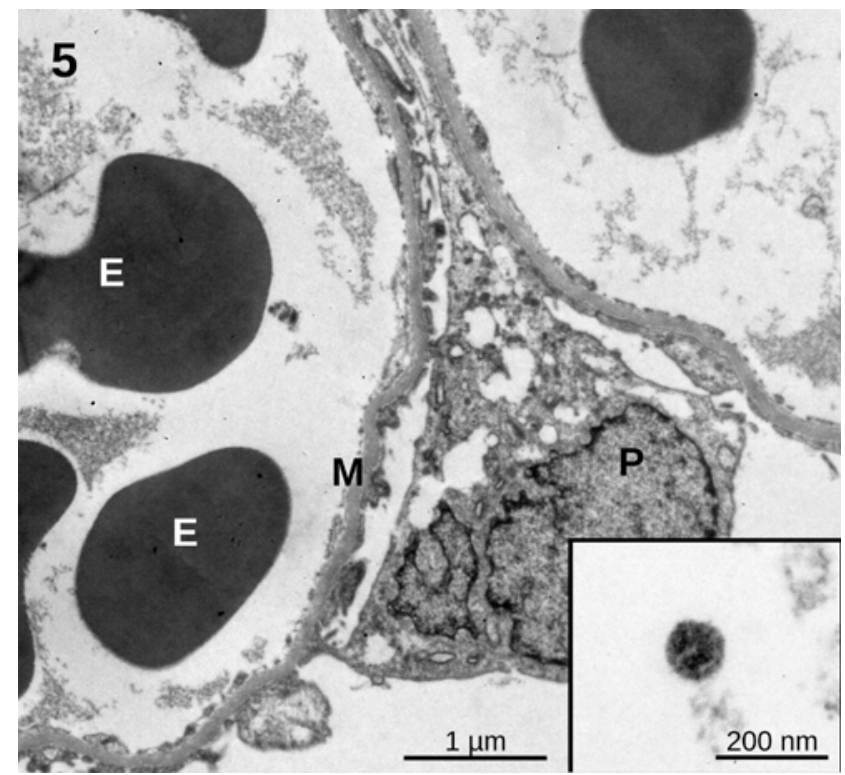

Paraffin-embedded material re-processed for electron microscopy.

\section{Figure 6}

Proximal convoluted tubule. Notice the extensive vacuolization of the cells and the presence of small $100 \mathrm{~nm}$ particles (arrows) that could represent virus particles.

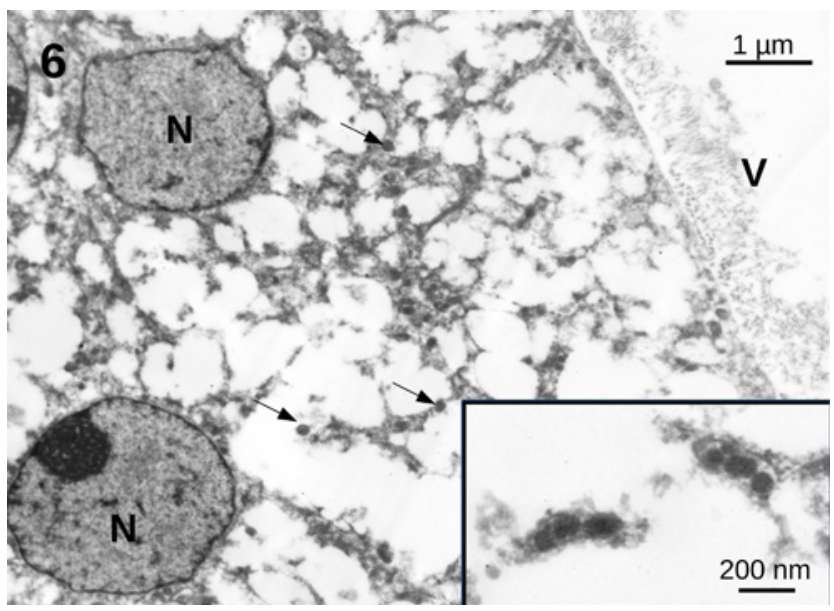

Large magnification of the particles. $\mathrm{N}$ - Nucleus; $\mathrm{V}$ - Microvilosities.

\section{DISCUSSION}

Acute kidney injury (AKI) is defined as an increase in $\mathrm{SCr}$ by 0.3 $\mathrm{mg} / \mathrm{dL}$ within 48 hours or a $50 \%$ increase from the baseline within 7 days, according to the Kidney Disease Improving Global Outcomes

\section{Figure 7}

Distal tubules.

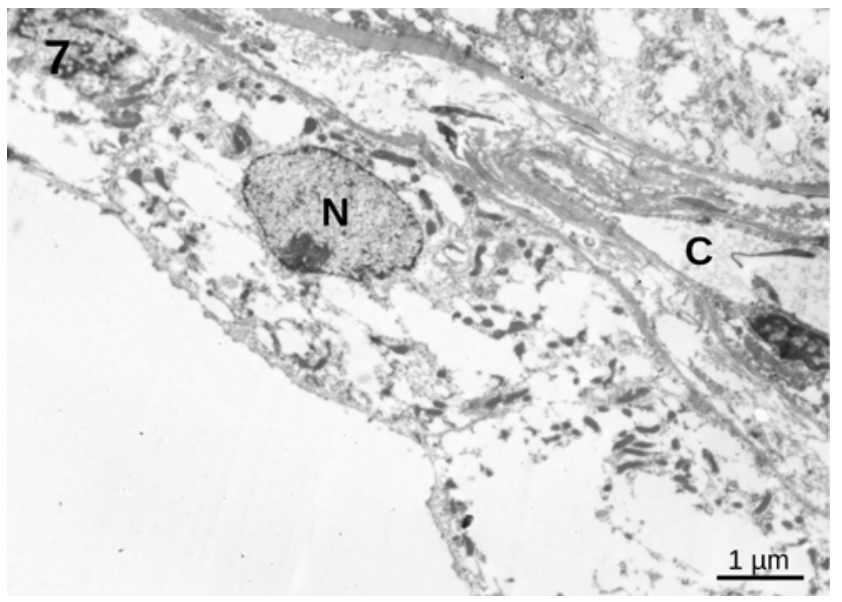

The cells show extensive vacuolization. $\mathrm{N}$ - Nucleus; $\mathrm{C}$ - capillary in the connective tissue.

\section{Figure 8}

Capillary in the connective tissue filled by a fibrillar cloth containing dense inclusions of unknown nature (arrows).

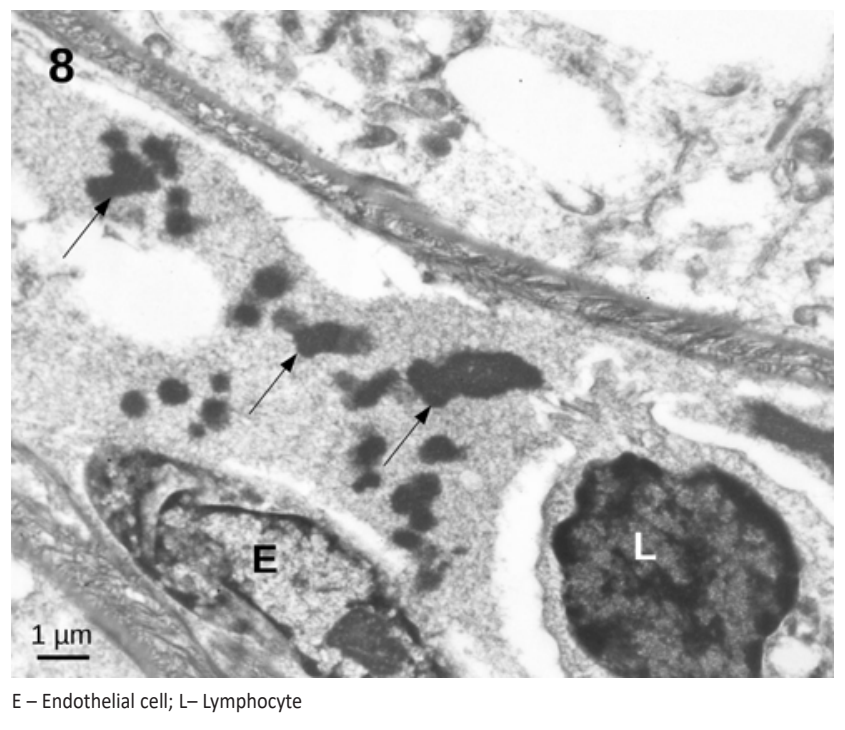

(KDIGO) criteria. ${ }^{3}$ Thus, according to our patient values, AKI stage III was recognized.

The first COVID-19 worldwide reports suggested a low incidence of kidney damage, but a higher frequency was later documented and AKI was classified as an independent risk factor for these patients' mortality. ${ }^{4}$ Most cases presented with microhematuria, mild proteinuria and increased blood urea nitrogen and serum creatinine with glomerular filtration rate decrease, all portending a worse prognosis. $^{5}$ 
Kidney involvement is most likely multifactorial, with sepsis leading to cytokine storm, diffuse proximal tubular injury or direct cellular injury by the virus via angiotensin-converting enzyme receptors being the predominant triggers ${ }^{6,7}$. Less commonly, iatrogenic damage by excessive diuretics and antiviral agents can occur. ${ }^{4}$ Notwithstanding the limited knowledge on the physiopathology and histology of the disease, six necropsy studies from China reported interstitial infiltration and collapsing glomerulopathy secondary to viral infection ${ }^{5}$. More recent biopsy studies showed multiple cases with glomerular involvement, particularly in patients with high risk APOL1 genotypes, from collapsing glomerulopathy to immune mediated conditions ${ }^{8}$. In all these conditions, cytokine-derived damage seems to be the culprit, since no direct viral infection was proven.

It is important to note the probable existence of a selection bias, whereby only patients with proteinuria and/or hematuria and kidney injury are biopsied. In most patients, the most probable injury mechanism is probably acute tubular necrosis due to sepsis, hypoxemia, clotting dysregulation and hemodynamic instability ${ }^{9,10}$.

Our case study, however, showed mainly tubular epithelium injury with acute tubular necrosis and multiple isometric vacuolization, possible due to direct viral infection, even without interstitial inflammation. However, this vacuolization is a non-specific lesion that can be seen in other pathologic conditions. Capillary clogs were also apparent and may be the cause of ischemia and kidney damage; however glomerular ischemia was not apparent. The origin of these clogs is unfortunately not completely understood, and is perhaps associated with viral infection or sepsis. The ultrastructural evaluation of the tubular proximal epithelium shows that there were few virus-like particles. The observed particles are of the right size for coronavirus, although details such as spikes could not be identified in the damaged sample pre-processed for paraffin histology. This supports our hypothesis of direct renal infection, even with negative RT-PCR. Negative PCR may be due to a low viral load, and is consistent throughout the literature. It is also not clear if those inclusions are viral related or a result of cellular damage ${ }^{11}$. However, existence of ACE2 receptors in both proximal tubule and the glomeruli make direct viral infection plausible but still inconclusive.

Because our patient was taking a high dose of Vitamin C, the presence of calcium oxalate crystals raises the hypothesis of vitamin C-induced oxalate nephropathy. Vitamin C is metabolized into oxalate and can induce AKI by precipitation of calcium oxalate in the renal tubules.

There are also a few reports of anecdotal kidney toxicity of ritonavir $^{12}$. Among them, a patient with two AKI episodes after starting two different antiretroviral therapies also took ritonavir and his histological alterations mimicked our patient's findings, such as tubular vacuolization $^{13}$. The absence of urinalysis hinders a possible clinical correlation with other findings.

We present multiple different findings in this kidney specimen. Even if it was impossible to affirm the existence of direct viral infection due to negative PCR, virus-like particles were observed. Importantly, capillary clogs, which may represent indirect viral damage due to ischemia were noted. Calcium oxalate crystals and tubular vacuolization secondary to putative supportive therapy highlight the potential danger in unproven treatment strategies.

\section{Disclosure of potential conflicts of interest: none declared.}

\section{References}

1. Marini JJ, Gattinoni L. Management of COVID-19 respiratory distress. JAMA. April 2020. doi:10.1001/jama.2020.6825

2. Organization WH. Coronavirus disease (COVID-19) situation reports.

3. Kellum JA, Lameire N, Aspelin P, et al. Kidney disease: Improving global outcomes (KDIGO) acute kidney injury work group. KDIGO clinical practice guideline for acute kidney injury. Kidney Int Suppl. 2012. doi:10.1038/kisup.2012.1

4. Cheng Y, Luo R, Wang K, et al. Kidney impairment is associated with in-hospital death of COVID-19 patients. medRxiv. 2020:2020.02.18.20023242. doi:10.1101/2020.02.18.20023242

5. Li Z, Wu M, Yao J, et al. Caution on kidney dysfunctions of COVID-19 patients. SSRN Electron J. 2020:1-25. doi:10.2139/ssrn.3559601

6. Du L, He Y, Zhou Y, Liu S, Zheng BJ, Jiang S. The spike protein of SARS-CoV - a target for vaccine and therapeutic development. Nat Rev Microbiol. 2009. doi:10.1038/nrmicro2090

7. Naicker S, Yang CW, Hwang SJ, Liu BC, Chen JH, Jha V. The Novel Coronavirus 2019 epidemic and kidneys. Kidney Int. 2020;97(5):824-828. doi:10.1016/j.kint.2020.03.001

8. Kudose S, Batal I, et al. Kidney biopsy findings in patients with COVID-19. JASN. 2020;31: 19591968.

9. Santoriello D, Khairallah P, et al. Postmortem kidney pathology findings in patients with COVID-19. JASN. 2020;31:2158-2167.

10. Sharma P, Uppal N, et al. COVID-19-associated kidney injury: a case series of kidney biopsy findings. JASN. 2020;31:1948-1958.

11. Cassol C, Gokden N, et al. Appearances can be deceiving - viral-like inclusiona in COVID-19 negative renal biopsies by electron microscopy. Kidney360. 2020;1:824-828.

12. Shafi T, Choi MJ, Racusen LC, et al. Ritonavir-induced acute kidney injury: kidney biopsy findings and review of literature. Clin Nephrol. 2011;75(1):60-64. doi:10.5414/CN106469

13. Chughlay MF, Njuguna C, Cohen K, Maartens G. Acute interstitial nephritis caused by lopinavir/ ritonavir in a surgeon receiving antiretroviral postexposure prophylaxis. Aids. 2015;29(4):503-504 doi:10.1097/QAD.0000000000000563

\section{ORCID}

Tiago Duarte (iD) 0000-0002-9806-0719

Fernando Caeiro iD 0000-0002-7294-1630

Mário Góis (iD) 0000-0002-0937-8611

António Matos (iD) 0000-0001-9386-0349

Helena Viana iD 0000-0002-7644-2230

César Vieira iD 0000-0003-3616-5440

Jorge Paulos (iD) 0000-0001-7443-9874

Paulo Paixão iD 0000-0002-4294-0872

Nuno Germano iD 0000-0003-4257-1197

Fernando Nolasco (iD) 0000-0002-7089-1975

\section{Correspondence to:}

Fernando Caeiro

Serviço de Nefrologia, Hospital Curry Cabral - CHLC

Rua da Beneficência $n$ ㅇ 8

1050-099 Lisboa

E-Email: 34550@chlc.min-saude.pt 